\title{
Tamoxifen for treatment of abnormal uterine bleeding in etonorgstrel implant users: a randomized clinical trial
}

\author{
Ahmed N. Fetih ${ }^{1}$, Ahmed M. Abbas ${ }^{1 *}$, Fatma A. Kamel ${ }^{2}$, Ihab H. El Nashar ${ }^{1}$ \\ ${ }^{1}$ Department of Obstetrics and Gynecology, Faculty of Medicine, Assiut University, Assiut, Egypt \\ ${ }^{2}$ Department of Obstetrics and Gynecology, Dairout Central Hospital, Assiut, Egypt \\ Received: 11 August 2019 \\ Accepted: 30 September 2019 \\ *Correspondence: \\ Dr. Ahmed M. Abbas, \\ E-mail: bmr90@hotmail.com \\ Copyright: (C) the author(s), publisher and licensee Medip Academy. This is an open-access article distributed under \\ the terms of the Creative Commons Attribution Non-Commercial License, which permits unrestricted non-commercial \\ use, distribution, and reproduction in any medium, provided the original work is properly cited.
}

\begin{abstract}
Background: The current study aims to compare the use of tamoxifen and oral contraceptive pills in women using implanon and complain with irregular uterine bleeding.

Methods: Women attended family planning clinic using implanon presented by bleeding were invited to participate in the study. They were randomized into two groups: Group A: 100 women received Tamoxifen 10 mg twice daily for 10 days taken at the onset of an episode of bleeding or spotting episode. Group B: 100 women received Combined oral contraceptive pills (microcept) once daily for 21 days take at the onset of an episode of bleeding or spotting episode.

Results: No difference regarding the baseline criteria of both groups. No difference between both groups regarding the duration of irregular bleeding in the implanon users $(\mathrm{p}=0.090)$. Additionally, the number of bleeding days and spotting in the last month was similar in both groups $(\mathrm{p}=0.554)$. The percentage of women who stopped bleeding during the period of treatment is $84 \%$ in the tamoxifen group and $92 \%$ in the COCs group, but the COCs needs longer treatment time, where the mean of days required to stop bleeding is $5.03 \pm 1.8$ days in the tamoxifen group and $6.5 \pm 2.5$ in the COCs group. Headache and nausea were the most prominent adverse effects found in the COCs group $(\mathrm{p}=0.000)$.

Conclusions: Oral administration of tamoxifen $10 \mathrm{mg}$ twice daily for 10 days is effective on stopping bleeding attacks in implanon users.
\end{abstract}

Keywords: Abnormal uterine bleeding, Contraception, Family planning, Implants, Oral contraceptives, Tamoxifen

\section{INTRODUCTION}

Dissatisfaction with bleeding patterns associated with hormonal contraception is a common reason for method discontinuation. Bleeding patterns with progestin implants range from frequent, unscheduled bleeding to amenorrhea. ${ }^{1}$ Most (75 to $80 \%$ ) implant users report unscheduled bleeding in the first 3 months of use. Though bleeding episodes can last for a long time, they are typically light consisting of spotting or light bleeding. Bleeding patterns in the first 3 months of use are predictive of patterns for the duration of use favorable bleeding patterns are likely to continue, while unfavorable bleeding patterns have a $50 \%$ likelihood of improvement .Unscheduled bleeding is the primary reason cited for implant discontinuation; approximately 6 to $23 \%$ of users who discontinue etonogestrel implants do so because of unscheduled bleeding. ${ }^{2}$ Prior to insertion, women should have an understanding of the high likelihood of unscheduled bleeding.

Expectant management is a mainstay of treatment for women who are experiencing unscheduled bleeding with a progestin implant. Implant users can also be given reassurance that there is $50 \%$ likelihood that bothersome 
bleeding patterns noted in the first 3 months of use will improve over time. For women who desire an intervention, a short course of NSAIDs or estrogen supplementation with estrogen alone or COCs is recommended by the USSPR. ${ }^{3}$ Courses of NSAIDs or using a COC are effective at reducing unscheduled bleeding, although bleeding typically recurs following treatment cessation.

The etiology of such bleeding is poorly understood over the past 35 years, five different World Health Organization workshops have attempted to investigate the pathogenesis. Part of the difficulty with identifying the predominant etiology is the multiple contributors to the problem. Unscheduled bleeding is likely influenced by type/dose of progestin, how the progestin is delivered, duration of use, and specific effect on the endometrium due to mechanism of action. The quantity/duration of bleeding may change between initiation of a method and continuation of that method. A leading cause of unscheduled bleeding with initiation is thought to be secondary to the rapid endometrial thinning effects of progestin. More practically, if women are going from relatively thick endometrium to relatively thin endometrium, it is biologically plausible that unscheduled bleeding/spotting will result as women continue their method, sustained exposure can lead to endometrial angiogenesis disruption, resulting in the development of a dense venous network that is fragile and prone to bleeding matrix metalloproteinases (MMP) are upregulated in the presence of progestin from hormonal contraceptives and contribute to the degradation of the endometrium. ${ }^{4-6}$

In the Implanon accumulating evidence supports the safety, efficacy, and acceptability of this contraceptive method. ${ }^{7}$ From 2011 to 2013, 0.8\% of women using contraception used an etonogestrel implant, up from 0.3 percent from 2006 to $2010 .^{8}$ A subdermal contraceptive implant is a single-rod, non-biodegradable implantable contraceptive that contains the progestin etonogestrel. The contraceptive efficacy of subdermal contraceptive implant was high, with zero pregnancies during treatment with subdermal contraceptive implant, resulting in a Pearl index of 0.0 (95\% confidence interval, 0.0 to 0.2 ) the subdermal contraceptive implant is a long-active progestogen-only contraceptive method that contains 68 mg etonogestrel. ${ }^{9}$

Tamoxifen is a selective estrogen receptor modulator (SERM) tamoxifen (TAM) is widely used as an adjuvant therapy for women with breast cancer (BC). However, TAM possesses partial estrogenic activity in the uterus and its use has been associated with an increased incidence of endometrial hyperplasia. The molecular mechanism for these observations is not well understood. Herein, authors demonstrated that forced expression of Trefoil factor 3 (TFF3), in estrogen receptor-positive $(\mathrm{ER}+)$ EC cells significantly increased cell cycle progression, cell survival, anchorage-independent growth, invasiveness and tumors growth in xenograft models. Tamoxifen (TAM), was the first SERM available for clinical use and has been regarded as a highly efficacious agent for the treatment of breast cancer, treatment of metastatic $\mathrm{BC}$, and reduction in $\mathrm{BC}$ incidence in high-risk women. ${ }^{10}$ These partial estrogenic actions of TAM produce beneficial effects on the skeletal and the cardiovascular system in postmenopausal women but are also associated with, endometrial hyperplasia, and EC use of a short course of tamoxifen, a selective estrogen receptor modulator (SERM), resulted in five fewer bleeding days and 15.2 more continuous days without bleeding compared to placebo in etonogestrel implant users. ${ }^{11,12}$

The current study aims to compare the use of tamoxifen and oral contraceptive pills in women using implanon and complain with irregular uterine bleeding.

\section{METHODS}

This study randomized controlled trial conducted at Assiut Women Health Hospital and Dairout Central Hospital with women coming to family planning clinic using implanon presented by bleeding.

\section{Inclusion criteria}

- The Female in reproductive age (18-45)

- Female used implanon for more than 3 months

- Female with irregular vaginal bleeding.

\section{Exclusion criteria}

- Undiagnosed abnormal uterine bleeding pre-dating placement of contraceptive

- Anticoagulation use

- Bleeding tendency

- Use of medication interfere with tamoxifen mechanism (Coumadin, letrozole, bromocriptine, rifampicin, aminoglutethimide, phenobarbital).

Data were collected using structured questionnaire through interview with the patient.

Women presently used implanon: duration of it's used? Where initiates the method? Receive counselling about the method, and had told to expect menstrual irregularities?

Women complaint and its effect on health; type and duration of increase or irregular bleeding abnormality \{intermenstrual bleeding, intermenstrual spotting, heavy or prolonged bleeding episode $\}$ Intermenstrual bleeding, previously known as metrorrhagia, is uterine bleeding at irregular intervals, particularly between the expected menstrual periods But the Intermenstrual spotting is the presence of apparent menstrual blood during the wrong parts of the menstrual cycle. ${ }^{13}$ Heavy or prolonged menstrual bleeding, also known as menorrhagia, it is 
menstrual bleeding that lasts for more than 7 days or when menstrual bleeding is heavy. Heavy bleeding is when a tampon or pad needs to be changed after less than 2 hours or if there are clots the size of a quarter or larger. ${ }^{14}$ No of (bleeding and spotting) days during last month, any other symptoms, previously visit a clinic for this abnormality, receive any investigation and medication and effect, ability to perform the household duties, bleeding influence any religious activity, affect sexual relation with husband and husband suggested terminate use the method and planning pregnancy in near future, previously asked for termination the method and not given the service.

Clinical examination (General and local) examination includes anthropometric measurement (height, weight, body mass index) blood pressure measurement and local examination to exclude any pelvic pathology.

Investigation: by transvaginal ultrasound to discover any local gynecological cause for the Bleeding, measuring endometrial thickness, and reporting any ovarian pathology.

\section{Then randomization was done through sealed envelope}

\section{Group A}

100 women received Tamoxifen $10 \mathrm{mg}$ twice daily for 10 days taken at the onset of an episode of bleeding or spotting episode.

\section{Group B}

100 women received combined oral contraceptive pills (microcept) once daily for 21days take at the onset of an episode of bleeding or spotting episode.

Follow up: at the end of the treatment
- At the end of the first month after beginning of the treatment

- At the end of the second month after beginning of the treatment

- At the end of the third month after beginning of the treatment.

At the first follow up: women asked if she had complete the treatment or not, the bleeding or spotting stopped or not, no of days required to stop current bleeding and spotting episode, if she did not complete the treatment asked about cause of discontinuation, and no of treatment days received.

At subsequent visits asked to report the change in menstrual pattern (no of bleeding and spotting days), side effect of the drug recorded and discontinuation duo to side effect reported.

\section{Statistical analysis}

The data were tabulated on SSPS (statistical Package for social science). Continuous variable was compared by ttest if parametric and by Mann whitney test if not parametric. Categorical variable were compared using X2 test or fisher exact test.

\section{RESULTS}

Two hundred women were randomly assigned to the tamoxifen Group $(n=100)$ and COCs Group $(n=100)$. No difference regarding the baseline criteria of both groups (Table 1).

Table 2 shows that there was no difference between both groups regarding the duration of irregular bleeding in the implanon users $(\mathrm{p}=0.090)$. Additionally, the number of bleeding days and spotting in the last month was similar in both groups $(\mathrm{p}=0.554)$.

Table 1: Demographic data of women participated in this study.

\begin{tabular}{|c|c|c|c|c|}
\hline & & $\begin{array}{l}\text { Group A (Tamoxifen) } \mathbf{N}=\mathbf{1 0 0} \\
\mathbf{N}(\%)\end{array}$ & $\begin{array}{l}\text { Group B (COCs) N=100 } \\
\text { N }(\%)\end{array}$ & P-value \\
\hline \multirow{3}{*}{ Age } & 18-35year & $74(\%)$ & $72(\%)$ & \multirow{3}{*}{0.750} \\
\hline & 36-45year & $26(\%)$ & $28(\%)$ & \\
\hline & Mean \pm SD & $33.3 \pm 4.7$ & $33.3 \pm 4.8$ & \\
\hline \multirow{3}{*}{ Level of education } & Illiterate & $43(\%)$ & $39(\%)$ & \multirow{3}{*}{0.135} \\
\hline & Some education & $45(\%)$ & $46(\%)$ & \\
\hline & University & $12(\%)$ & $15(\%)$ & \\
\hline \multirow{3}{*}{$\begin{array}{l}\text { Husband level of } \\
\text { education }\end{array}$} & Illiterate & $20(\%)$ & $14(\%)$ & \multirow{3}{*}{0.343} \\
\hline & Some education & $72(\%)$ & $73(\%)$ & \\
\hline & University & $8(\%)$ & $13(\%)$ & \\
\hline No of living children & Mean \pm SD & $3.3 \pm 1.6$ & $4.6 \pm 1.7$ & 0.502 \\
\hline BMI & Mean \pm SD & $31.9 \pm 3.2$ & $31.7 \pm 3.9$ & 0.243 \\
\hline
\end{tabular}

COCs: combined oral contraceptives, BMI: body mass index, SD: standard deviation. 
Table 2: Duration of menstrual irregularities.

\begin{tabular}{|llll|}
\hline & Group A (Tamoxifen) $\mathbf{N}=100$ & Group B (COCs) N=100 & P-value \\
\hline Duration of irregular bleeding by (months) & $4.9 \pm 2.6$ & $5.4 \pm 1.9$ & 0.090 \\
\hline $\begin{array}{l}\text { Number of bleeding days and spotting in } \\
\text { the last month }\end{array}$ & $13.4 \pm 3.9$ & $13.6 \pm 3.8$ & 0.554 \\
\hline
\end{tabular}

COCs: combined oral contraceptives.

Table 3: Effect of treatment on irregular bleeding in both groups.

\begin{tabular}{|c|c|c|c|c|c|}
\hline & Group A ( & ifen) $\mathrm{N}=100$ & Group B (C & Ss) $\mathbf{N}=\mathbf{1 0 0}$ & P-value \\
\hline \multirow{2}{*}{$\begin{array}{l}\text { Bleeding stopped } \\
\text { after treatment }\end{array}$} & Yes & No & Yes & No & \multirow{2}{*}{ 0.005* } \\
\hline & $84(84 \%)$ & $16(16 \%)$ & $92(92 \%)$ & $8(8 \%)$ & \\
\hline \multirow{6}{*}{$\begin{array}{l}\text { No of days required } \\
\text { to stop bleeding }\end{array}$} & $N=84$ & & $\mathrm{~N}=92$ & & \multirow{5}{*}{$0.001 *$} \\
\hline & $1-3$ day & $27(32 \%)$ & $1-3$ days & $13(14.2 \%)$ & \\
\hline & 4-7 day & $51(60.7 \%)$ & 4-7 days & $56(60.8)$ & \\
\hline & 8-10 day & $6(7.2 \%)$ & 8-10 days & $16(17.4 \%)$ & \\
\hline & $11-21$ day & - & 11-21 days & $7(7.6 \%)$ & \\
\hline & Mean \pm SD & $5.03 \pm 1.8$ & Mean \pm SD & $6.5 \pm 2.5$ & $0.000 *$ \\
\hline \multirow{4}{*}{$\begin{array}{l}\text { Percentage of woman } \\
\text { did not stop bleeding } \\
\text { during treatment }\end{array}$} & In 3 days & $73(73 \%)$ & In 3 days & $87(\%)$ & \multirow{4}{*}{$0.005 *$} \\
\hline & In 7 days & $27(27 \%)$ & In 7 days & $31(\%)$ & \\
\hline & In 10 days & $16(16 \%)$ & In 10 days & $15(\%)$ & \\
\hline & In 21days & - & In 21 days & $8(\%)$ & \\
\hline
\end{tabular}

*Statistically significant difference, COCs: combined oral contraceptives.

Table 4: Side effects of the medications in both groups.

\begin{tabular}{|c|c|c|c|}
\hline Side effects & Group A (Tamoxifen) $\mathbf{N}=\mathbf{1 0 0}$ & Group B (COCs) N=100 & P-value \\
\hline None & $33(\%)$ & $12(\%)$ & $0.001 *$ \\
\hline Hot flushes & $18(\%)$ & $12(\%)$ & 0.434 \\
\hline Mood change & $13(\%)$ & $12(\%)$ & 0.904 \\
\hline Headache & $12(\%)$ & $52(\%)$ & $0.000^{*}$ \\
\hline Nausea & $5(\%)$ & $28(\%)$ & $0.000^{*}$ \\
\hline Weakness & $2(\%)$ & $6(\%)$ & 0.351 \\
\hline Breast tenderness & $2(\%)$ & $0(\%)$ & 0.357 \\
\hline Complicated implant removal & $5(\%)$ & $4(\%)$ & 0.916 \\
\hline Planned implant removal & $3(\%)$ & $0(\%)$ & 0.211 \\
\hline
\end{tabular}

*Statistically significant difference.

The percentage of women who stopped bleeding during the period of treatment is $84 \%$ in the tamoxifen group and $92 \%$ in the COCs group, but the COCs needs longer treatment time, where the mean of days required to stop bleeding is $5.03 \pm 1.8$ days in the tamoxifen group and $6.5 \pm 2.5$ in the COCs group (Table 3 ).

Table 4 shows the side effects encountered during the course of treatment in both groups. Headache and nausea were the most prominent adverse effects found in the COCs group $(\mathrm{p}=0.000)$.

\section{DISCUSSION}

This is not the first trial, to our knowledge, reporting the use of tamoxifen in the treatment of bleeding irregularities associated with implanon use. Among etonorgestrel implant users with frequent or prolonged bleeding, the first use of tamoxifen leading to statistically significant and clinically important short-term improvements in bleeding, with a reduction in $\mathrm{B} / \mathrm{S}$ days in the 3 months following treatment. The use of tamoxifen in this study is less effective than COCs in stopping bleeding and women's satisfaction after treatment. Effects of tamoxifen treatment continue 3 months after use. However, with the use of COCs, women suffer many complications and return bleeding disorders as they were before treatment two months later just.

A series of clinical trials have been tried using different breakthrough bleeding management strategies associated with the use of implanon. This included the use of combined oral contraceptives, tranexamic acid, ethinyl estradiol, ibuprofen mefenamic acid and vitamin E. ${ }^{15-19}$ It was found that the effects of the drugs mentioned above 
in reducing the duration of the days of bleeding more effective compared to the placebo. the effect of tamoxifen must be confirmed by a larger randomized controlled trial.

Grow and Reece have suggested an explanation for the above beneficial effect of SERMs. ${ }^{20}$ They based their explanation upon the results of in vitro trials demonstrating that endometrial aberrant revascularization may be estrogen-dependent rather than progestogendependent. Anti- progesterone's (noncompetitive antiestrogens) theoretically may have the capacity to inhibit the growth of these abnormal vessels by its estrogen antagonism properties. Laboratory animals treated with mifepristone (anti-progesterone had significantly lower VEGF-R1 (estrogen-responsive mitogens) relative to the control animals.

Williams et al, showed that castrated monkeys treated with noncompetitive estrogen antagonist (onapristone) experienced a 10-fold reduction in the incidence of breakthrough bleeding relative to the placebo. ${ }^{21}$ Authors can propose a similar mechanism for the effect of tamoxifen (competitive anti-estrogen). Additionally, nonhuman primate trials demonstrated the antiangiogenic action of tamoxifen. Tamoxifen was capable of decreasing the number of blood vessels in the nude mice carcinoma of the breast by $68 \% .^{22}$ Tamoxifen and antiprogestins inhibit angiogenesis in the chick egg chorio allantoic membrane, and this anti- angiogenic action is independent of estrogen receptor action. ${ }^{23}$ This inhibition of angiogenesis was even observed in the presence of fivefold increased concentrations of 17estradiol. This suggests anti-angiogenic action that is that is independent of the estrogen receptor. The effects of tamoxifen have been demonstrated in the uteri of rats, where treatment causes a decrease in uterine weight, epithelial thickness and number of glands. ${ }^{24}$

The theoretical concern of the possible interference of tamoxifen treatment with the efficacy of the contraceptive implant cannot be ignored. Although the present study was not designed to answer this question, no case of pregnancy was reported. Tamoxifen has rarely been combined with Progestin. One report showed profound suppression of both estrogen and progesterone receptors in the endometrium, which was atrophic and decidualized. ${ }^{25}$ In conclusion, tamoxifen could have a role in the treatment of vaginal bleeding irregularities associated with POCs. The improvement in bleeding pattern which lasted for 3 months after treatment is also appealing.

The mechanism of action of tamoxifen on the endometrium differs from COCs, offering a possible explanation for the difference in duration of treatment effect with these two therapies. During etonorgestrel implant use, the combination of follicular phase levels of estrogen and high levels of progestin produce a decidualized endometrium containing a high concentration of thin-walled venules and capillaries that may be prone to Unpredictable bleeding, although the exact of action is unknown, COCs likely temporarily interrupt breakthrough bleeding through endometrial proliferation stimulated by the estrogen component. ${ }^{26}$ Discontinuation of the COC removes the proliferative effect, once again exposing the unstable vascular pattern. Estrogen action is mediated through two receptors, estrogen receptor $\alpha(E R \alpha)$ and estrogen receptor $\beta$ (ER $\beta)$. The proliferative, mitogenic effects of estrogen in the endometrium are mediated by ER $\alpha$. In contrast, estrogen action in the endometrial vascular endothelium is primarily regulated by ER $\beta .^{27}$ As a pure ER $\beta$ antagonist; tamoxifen may improve endothelial stability through antagonism of this receptor, potentially leading to prolonged cessation of bleeding by down-regulation of angiogenesis. ${ }^{20}$

Combined estrogen and progestin versus placebo (therapeutic treatment for LNG subcutaneous implant users; $n=2$ studies) There were two studies: AlvarezSanchez 1996, Witjaksono 1996, in which a combination of oral ethinyl estradiol and oral lenovorgestrel was tested as a means to treat bleeding irregularities in Norplant users. $^{28,29}$ The two studies together randomized 66 women to receive the treatment regimen and 64 to receive placebo; of these 61 and 60, respectively, were included in the analyses, Alvarez-Sanchez 1996 reported efficacy in terms of the percentage of women who experienced a cessation of bleeding within 3 days of treatment; the Witjaksono 1996 paper reported the number of bleeding days and episodes in 90-day reference periods. According to the reports of the author and in the former study, the combined approach significantly reduced continued irregular bleeding during treatment, when compared with placebo and reduced unacceptable bleeding after treatment (as defined by the number of women experiencing bleed-free intervals of less than 11 days). Witjaksono 1996 did not report discontinuations or side effects in the study results but (Alvarez-Sanchez 1996) reported that the discontinuation of Norplant due to bleeding disturbances was not significantly different between women in the combined hormone treatment and placebo groups, Discontinuation due to the side effects of the treatment did not differ between groups; however, our analysis differ of the Alvarez-Sanchez data revealed a higher incidence of reported side effects (nausea or gastralgia) in the microcept treatment group than in the tamoxifen group.

\section{CONCLUSION}

In conclusion, oral administration of tamoxifen $10 \mathrm{mg}$ twice daily for 10 days is effective on stopping bleeding attacks in implanon users.

Funding: No funding sources

Conflict of interest: None declared

Ethical approval: The study was approved by the Institutional Ethics Committee 


\section{REFERENCES}

1. Abdel-Aleem H, d'Arcangues C, Gaffield KMV, Gülmezogl AM. Treatment of vaginal bleeding irregularities induced by progestin only contraceptives. Cochrane Database Syst Rev. 2013;10:1002-465.

2. Petra M, CaseyMargaret E, LongMary L, MarnachJessica EB. Bleeding related to etonogestrel subdermal implant in a US population. Contracept. 2011;83:426-30.

3. Curtis KM, Tepper NK, Jatlaoui TC, Berry-Bibee E, Horton LG, Zapata LB, et al. U.S. selected practice recommendations for contraceptive use; 2016;65:1-66.

4. Speroff L, Darney PD. A clinical guide for contraception. Lippincott Williams and Wilkins; 2010.

5. ESHRE Capri Workshop Group. Ovarian and endometrial function during hormonal contraception. Human Reprod. 2001;16(7):1527-35.

6. Kaneshiro B, Edelman A, Dash C, Pandhare J, Soli FM, Jensen JT. Effect of oral contraceptives and doxycycline on endometrial MMP-2 and MMP-9 activity. Contracept. 2016;93:65-9

7. Winner B, Peipert JF, Zhao Q, Buckel C, Madden T, Allsworth JE, et al. Effectiveness of long-acting reversible contraception. N Engl J Med. 2012;21: 366.

8. Branum AM, Jones J. Trends in long-acting reversible contraception use among U.S. women aged 15-44. NCHS Data Brief. 2015;188:1-8.

9. Balogun OR, Olaomo N, Adeniran AS, Fawole AA. Implanon subdermal implant: an emerging method of contraception in Ilorin.2014:3:1-5.

10. [10] Spring LM, Gupta A, Reynolds KL, Gadd MA, Ellisen LW, Isakoff SJ, et al. Neoadjuvant endocrine therapy for estrogen receptor-positive breast cancer. A systematic review and meta-analysis. JAMA Oncol. 2016;2:1477-86.

11. $\mathrm{Hu} \mathrm{R}$, Hilakivi-Clarke L, Clarke R. Molecular mechanisms of tamoxifen-associated endometrial cancer. Oncology Letters. 2015;9(4):1495-501.

12. Simmons KB, Edelman AB, Fu R, Jensen JT. Tamoxifen for the treatment of breakthrough bleeding with the etonogestrel implant: a randomized controlled trial. Contracept. 2017;2:198-204.

13. Bacon JL. Abnormal uterine bleeding: current classification and clinical management. Obstet Gynecol Clin North America. 2017;44:179-93.

14. American College of Obstetricians and Gynecologists. ACOG committee opinion no. 557: Management of acute abnormal uterine bleeding in nonpregnant reproductive-aged women. Obstet Gynecol. 2013;121:891.

15. Hou MY, McNicholas C, Creinin MD. Combined oral contraceptive treatment for bleeding complaints with the etonogestrel contraceptive implant: a randomized controlled trial. Eu J Contracept Repro Health Care. 2016;15:1-6.

16. Sordal T, Inki P, Draeby J, O'Flynn M, Schmelter T. Management of initial bleeding or spotting after levonorgestrel-releasing intrauterines system placement: a randomized controlled trial. Obstet Gynecol. 2013;121:934-41.

17. Diaz S, Croxatto HB, Pavez M, Belhadj H, Stern J, Sivin I. Clinical assessment of treatments for prolonged bleeding in users of Norplantn implants. Contracept. 1990;42:97-109.

18. Tantiwattanakul P, Taneepanichskul S. Effect of mefenamic acid on controlling irregular uterine bleeding in DMPA users. Contracept. 2004:70:277-9.

19. Subakir SB, Setiadi E, Affandi B, Pringgoutomo S, Freisleben HJ. Benefits of vitamin E supplementation to Norplant users in vitro and in vivo studies. Toxicol. 2000; $148: 173-8$

20. Grow DR, Reece MT. The role of selective estrogen receptor modulators in the treatment of endometrial bleeding in women using long-acting progestin contraception. Hum Reprod. 2000;15:1-6.

21. Williams RF, Kloosterboer JH, Verbost PM, Hodgen GD. Once monthly antiprogestin controls menstrual bleeding during progestin- only contraception in primates. J Soc Gynecol Investig. 1997;4:134A.

22. Lindner DJ, Borden EC. Effects of tamoxifen and interferon-beta or the combination on tumor-induced angiogenesis. Int J Cancer. 1997;71:456-1.

23. Gagliardi A, Collins DC. Inhibition of angiogenesis by antiestrogens. Cancer Res. 1993;53:533-5.

24. Patriarca MT, Simoes RD, Smaniotto S. Morphological action of tamoxifen in the endometrium of persistent estrous rats. Acta Obstet Gynecol Scand. 1996;75:70710.

25. Cohen I, Beyth Y, Altaras MM. Estrogen and progesterone receptor expression in postmenopausal tamoxifen-exposed endometrial pathologies. Gynecol Oncol. 1997;67:8-15.

26. Hickey M, Fraser IS. Surface vascularization and endometrial appearance in women with menorrhagia or using levonorgestrel contraceptive implants. Implications for the mechanisms of break- through bleeding. Hum Reprod. 2002;17:2428-34.

27. Critchley H, Brenner RM, Henderson TA, Williams K, Nayak NR, Slayden OD. Estrogen receptor beta, but not estrogen receptor alpha, is present in the vascular endothelium of the human and nonhuman primate endometrium. J Clin Endocrinal Metab. 2001;86:13708.

28. Alvarez-Sanchez F, Brache V, Thevenin F, Cochon L, Faundes A. Hormonal treatment for bleeding irregularities in Norplant implant users. Am J Obstet Gynecol. 1996;174:919-22.

29. Witjaksono J, Lau TM, Affandi B, Rogers PA. Oestrogentreatment for increased bleeding in Norplant users: preliminary results. Human Reprod. 1996;11:109-14.

Cite this article as: Fetih AN, Abbas AM, Kamel FA, El Nashar IH. Tamoxifen for treatment of abnormal uterine bleeding in etonorgstrel implant users: a randomized clinical trial. Int J Reprod Contracept Obstet Gynecol 2019;8:4462-7. 